\title{
Democracia, Micropolítica e os Dispositivos de Gestão Educacional Gerencial
}

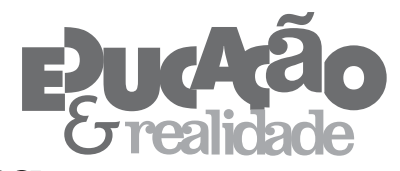

\author{
André Antunes Martins ${ }^{1}$ \\ 'Universidade Federal Fluminense (UFF), Niterói/RJ - Brasil
}

RESUMO - Democracia, Micropolítica e os Dispositivos de Gestão Educacional Gerencial. O artigo problematiza o direcionamento das políticas públicas à ampliação do exercício da democracia em educação, fazendo referências às capturas que a gestão gerencial promove ao referendar os valores de mercado. Da mesma forma, analisamos a formação do Estado moderno em sua função de codificador dos fluxos e produtor de territórios vinculados à sociedade de controle. Nesse contexto, o campo educacional, em seus aspectos organizativos e formativos, é atravessado pelo controle, disseminados pela racionalidade econômica. No entanto, as desterritorializações promovem fissuras na racionalidade econômica liberal, a educação menor seria um exemplo desse fluxo desterritorializante democrático em educação.

Palavras-chave: Educação. Democracia. Gestão Gerencial. Micropolítica. Desterritorialização.

ABSTRACT - Democracy, Micropolitics and Tools of Business Management Education. The article discusses the direction of public policiesy to expand the exercise of democracy in education, by making reference to the control that corporate management promotes to confirm market values. Likewise, we analyse the formation of the modern State in its function as codifier of the flows and producer of territories linked to the society of control. In this context, the educational field, in its organizational and formative aspects, is crossed by control, disseminated by economic rationality. However, the deterritorialization causes cracks in the liberal economic rationality, and the minor education would be an example of this democratic deterritorializing flow in education.

Keywords: Education. Democracy. Business Management. Micropolitics and Deterritorialization.

Educação \& Realidade, Porto Alegre, v. 41, n. 2, p. 453-465, abr./jun. 2016. 453 http://dx.doi.org/10.1590/2175-623654948 


\section{Introdução}

Esse estudo nasce da vontade de expressar um campo de atuação político educacional ainda pouco conhecido, ou pouco compreendido, não somente em relação aos possíveis leitores, mas também como reflexão autodirigida. Ele permite uma espécie de apresentação aos outros e a nós mesmos do que fazemos; e ainda dos acontecimentos que podemos provocar em educação.

Neste artigo, há um deslocamento significativo das tradicionais formas de fazer pesquisa, pois importa-nos vivenciar as relações onde o novo está sendo inventado, não se tratando de descobrir verdades escondidas ou de promover redenção por um conhecimento revelado, mas de participar das diversas - e até adversas - novidades do acontecimento educacional. Pesquisar é criar; e criar é problematizar (Tadeu; Corazza; Zordan, 2004). O estudo problematiza o direcionamento das políticas públicas à ampliação do exercício da democracia em educação, fazendo referências às capturas que a gestão gerencial promove ao referendar os valores de mercado. Para melhor entendimento, analisamos, no primeiro momento, os dispositivos de participação democrática no contexto da reforma de Estado a partir dos anos 1990; e o quanto esses objetivos de alargar a participação estão envoltos numa adequação da educação à intensificação da ressemantização de conceitos e práticas, em consonância com a racionalidade econômica voltada à produção da educação eficaz.

No segundo momento, discutimos a micropolítica deleuziana tomando a formação do Estado moderno em sua função de codificador dos fluxos (entre eles, o exercício da democracia) e produtor de territórios vinculados à sociedade de controle. Nesse contexto, o campo educacional é analisado considerando os aspectos organizativos e formativos atravessados pelos fluxos de controle, disseminados pela racionalidade econômica. A gestão pela democracia (gerencial) vem sendo dispositivo de controle e produtividade ao promover a formação para expansão do capital e ao territorializar os fluxos/fugas não adequados. Doutra forma, a micropolítica, sobretudo, diz sobre a política do acontecimento, das intensidades das desterritorializações que promovem fissuras na racionalidade econômica liberal. A educação menor seria um exemplo desse fluxo desterritorializante democrático no campo educacional.

\section{Democracia e a Gestão Educacional Gerencial}

O campo educacional vem experimentando mudanças em sua organização com a introdução de diversos dispositivos que dizem sobre uma participação direta nos processos deliberativos, em boa parte, não exclusivamente, reivindicados pelos movimentos em defesa da educação pública no contexto da redemocratização. 
Em concomitância, a democracia participativa tem sido apresentada como forma eficaz de organização para o momento atual de desenvolvimento econômico e político. Os Objetivos de Desenvolvimento do Milênio (ODM), documento anunciado pela Organização das Nações Unidas (ONU), o qual tem o Brasil como signatário, estabelece metas para o terceiro milênio de um mundo mais pacífico, justo e sustentável, como também, entre as metas específicas, promover a educação básica de qualidade para todos. Esse documento, divulgado pela Secretaria Geral da Presidência da República, alega que a melhor forma para alcançar tais objetivos seria por meio da democracia participativa, da vontade popular e de um novo diálogo entre o Estado e a sociedade civil (Brasil, 2011).

Nesse cenário, as críticas às diferentes formas de representação, como aos partidos e seus políticos profissionais, ao Congresso Nacional, aos gestores educacionais (responsáveis pela formulação das políticas), entre outros, expressam um descontentamento crescente à democracia representativa. Agrega-se a esse contexto a introdução dos mecanismos de gestão gerencial que avançam, concomitantemente e em hibridização, com os discursos e as ações de alargamento da participação democrática.

Não são poucos os trabalhos que apresentam análises sobre o desenvolvimento da democracia na contemporaneidade. Entre esses, Santos e Avritzer (2005) tecem críticas ao cânone democrático liberal ao exporem a pretensão de universalidade e exclusividade; e o quanto esse modelo contrapor-se-ia à demodiversidade, qualificada por práticas participativas e plurais. Apontam, ainda, a existência de combinações entre elas: pela coexistência e pela complementaridade.

Na coexistência, há, como o nome indica, uma convivência das formas de procedimentalismo representativo e organização administrativa com a variação do desenho institucional (mais próximo da participação direta). Na complementaridade, existe uma articulação entre representatividade e participação, sendo aceita a ideia de que o procedimentalismo participativo, as formas públicas de monitoramento dos governos e os processos de deliberação podem substituir parte das formas representativas (Santos; Avritzer, 2005).

Para os autores, a perda de força e credibilidade da demodiversidade ou das práticas políticas alternativas, ao mesmo tempo, embalou o modelo de democracia liberal, contando, para isso, com aportes financeiros do Banco Mundial e do Fundo Monetário Internacional no contexto de ampliação da globalização neoliberal (Santos; Avritzer, 2005). A análise desenvolve-se na tentativa de elucidar as práticas democráticas alternativas que não aceitaram a inexorabilidade da democracia liberal, caracterizada pela baixa intensidade participativa. O que não fica explicitado é a imbricação e o uso dos conceitos e práticas participativas como elementos associados ao campo neoliberal.

Educação \& Realidade, Porto Alegre, v. 41, n. 2, p. 453-465, abr./jun. 2016. 
Democracia, Micropolítica e os Dispositivos de Gestão Educacional Gerencial

Em estudo recente, João Pereira (2008) analisa o desenvolvimento da política de governança no âmbito do Banco Mundial, nos idos dos anos 1990. A governança pautou-se numa gestão que promovia uma adequação das políticas de Estado, sobretudo dos países periféricos, ao ajustamento neoliberal. Ou seja, construir um ambiente amigável ao mercado, com mudanças (organizacionais) promovidas pelos próprios Estados, diminuindo a necessidade de uma intervenção direta (na economia). Para dar consecução à ideia de uma gestão pública eficiente, concebeu-se a articulação de órgãos estatais e organizações sociais como elemento essencial à boa governança. Essa articulação se daria pela diminuição da intervenção do Estado por meio da descentralização administrativa, promovendo a participação social nos níveis mais baixos dos governos, incluindo o campo educacional. O autor enfatiza que houve uma divisão de trabalho muito clara entre os níveis decisórios: aqueles de cima que manejavam estrategicamente a macroeconomia e as reformas estruturais sem controle democrático; e os de baixo que colaboravam nos projetos e políticas públicas no âmbito social (educacional) e ambiental.

Esse arranjo encaminhado pelos organismos internacionais, emoldurado pelo Consenso de Washington, foi peremptório na definição da reforma de Estado no Brasil. A modernização do Estado brasileiro, e sua consequente adequação a um novo panorama da economia mundial, acontece nesse cenário de reformas estruturantes, assim como o próprio ajuste organizativo da educação aos valores participativos de culto ao espírito empreendedor.

No entanto, há argumentos (aparentemente) contrários à tese de que o ajustamento político econômico, pelo incremento da democracia gerencial, tenha sido o caminho adotado. A democracia teria sido tomada como irrelevante numa economia de mercado global, e, até mesmo, empecilho à eficiência. Logo, cortes nos gastos do Estado, privatização dos serviços públicos, intensificação de organismos supranacionais na definição dos orçamentos e salários, o temor de existência de barreiras nas necessárias adequações neoliberais, etc. indicariam um descredenciamento da democracia como forma de incentivar as sociedades aos imperativos do mercado (Streeck, 2014).

Acreditamos que as duas compreensões não são excludentes. De fato, a democracia preconizada como forma de aumentar a eficiência das ações de Estado tem ojeriza à efetiva participação popular e a qualquer deliberação desviante do script definido nas cúpulas (e suas redes). Portanto, a democracia de baixa intensidade apresentada não é incompatível com o projeto de reforma e implementação de ajustes neoliberais.

Não sem razão, Rancière (2014) argumenta sobre o caráter oligárquico da democracia, na medida em que age aprisionando a ação política comum à vida pública, impondo limites que objetivam restringi-la a 
um universalismo privatizado pelo nascimento, riqueza e competência. Diz-nos o autor sobre a ideologia republicana democrática que está confinada ao reino da lei e à ilimitação da expansão da riqueza capitalista. Esse republicanismo, que se faz presente deste muito tempo entre nós, recusa diuturnamente a democracia na manifestação de sua expansão ilimitada e invenção constante, as quais contrariam a privatização do público.

O ódio à democracia estaria explicado, portanto, ao explicitarmos seu movimento de não adequação ao político-jurídico instituído pela oligarquia democrática. Logo, novamente podemos afirmar, não há incompatibilidade na rejeição dessa democracia nas reformas e nos ajustes neoliberais, como também, na ação dispensada em torná-la congruente com as perspectivas gerencialistas da racionalidade econômica.

Como corolário, não seria forçoso nem inadequado admitir, bem longe disso, que as reformas que se constituem a partir dos anos 1990 no Brasil introduzem elementos alinhados ao neoliberalismo, transformando pautas históricas das lutas dos movimentos, em defesa da educação pública, em mecanismos vinculados ao gerencialismo. Incentivadas pelos organismos internacionais nos países periféricos, as reformas continuam avançando na afirmação da prevalência do setor privado como ator importante dentro do sistema educacional, ratificando a ideia de educação como mercado emergente e, para isso, o discurso de melhor performance e eficácia do setor é usado para enfraquecer as instâncias educacionais públicas, inclusive por meio das parcerias público-privadas e da formação de alunos empreendedores mais predispostos aos novos tempos do modelo produtivo pós-fordista (Robertson, 2012).

Nesse processo, a ressemantização dos conceitos, em acordo com as reformas liberalizantes, vem capturando manifestações democráticas com a introdução da racionalidade econômica na gestão da educação pública (Oliveira, 2011). Considerando um contexto territorial mais amplo das reformas, Licínio Lima (2008) argumenta que a reconceitualização dos termos como autonomia, descentralização e participação as despojou de sentido político. A autonomia tornou-se instrumento na construção de uma cultura da organização empresarial; a descentralização estaria relacionada à ordem espontânea do mercado e das relações individualizadas; e a participação reduzida a uma técnica de gestão para a coesão e o consenso.

As reformas tiveram como um de seus argumentos a ideia de que era preciso encontrar uma nova equação para o desenvolvimento, pautada, sobretudo, pela superação da concepção de um Estado financiador exclusivo dos direitos sociais. Martins (2013), ao analisá-las por meio dos argumentos do ex-ministro Bresser Pereira, apresenta as nuances de um neoliberalismo matizado por um Estado social-liberal (conforme 
Democracia, Micropolítica e os Dispositivos de Gestão Educacional Gerencial

definição do próprio Pereira), com intuito principal de garantir as propriedades e os contratos, a promoção da competitividade e os direitos sociais. A fórmula encontrada para a garantia desses direitos sociais foi a introdução das parcerias público-privadas. Nessa nova arquitetura, houve a assertiva de que as atividades públicas, como a educação, entregues à administração pública gerencial, demandariam uma espécie de controle social por meio da organização dos diversos conselhos de acompanhamento. A democracia, nesse sentido, foi alçada como regime fundamental à reconstrução do Estado.

Não devemos negligenciar que essa participação democrática é parte da estratégia para fomentar o desempenho eficaz da gestão educacional, pois instituições autônomas, descentralizadas/desconcentradas passam a ser responsabilidade dos gestores/educadores como do cidadão/cliente, legitimador dos serviços e dos resultados pela ótica do mercado (Adrião, 2006). A participação colaboração/coesão afirma a técnica de gestão para reduzir os conflitos e pacificar os processos na direção da educação de qualidade eficaz (Lima, 2008).

Em decorrência disso, temos a adequação da democracia aos preceitos do gerencialismo, a qual se apresenta por meio da intensificação dos sistemas de responsabilização e meritocracia. Freitas (2011) comenta sobre a proposta de uma ONG, bem atuante na definição das políticas educacionais, de que o Brasil deveria copiar o sistema de charters schools dos Estados Unidos, definidas como escolas públicas privatizadas que funcionam cumprindo metas. Essa mesma ONG, de acordo com o autor, chama o processo de privatização das escolas de gestão autônoma da Educação Básica, num evidente eufemismo na vinculação da educação aos aspectos mercadológicos.

Fica explicitado que a autonomia de gestão almejada está em consonância com a lógica de negócios, com o desenvolvimento de uma cultura da organização empresarial a qual deve pautar o campo educacional público em vias de privatização. Não a composição democrática, mas a concorrência no cumprimento das metas, promovendo a intensidade de competição entre as escolas e professores por financiamento, bônus salarial, reconhecimento de seu empreendedorismo etc. São preceitos orientadores de uma ideia de participação e de qualidade articuladas ao mercado.

Portanto, não sem preocupação, o exercício da democracia nos espaços educacionais, deve ser compreendido pelos enlaces neoliberalizantes que embasam as políticas educacionais atuais. Os mecanismos participativos e colegiados em vigor, embora também apontem as expressões dos movimentos em defesa da educação pública, não podem ser concebidos desconectados das orientações do gerencialismo contemporâneo. 


\title{
Micropolítica Deleuziana e Des/Territorializações Educacionais
}

Na perspectiva deleuziana, o Estado na sociedade capitalista cumpre a função de controlador/codificador do movimento (duplo) promovido pela ação do capital. Pois, o capital, ao se desterritorializar amplificando continuamente os fluxos produtivos, incumbe o Estado dos processos de codificação, como modo de impedir a ruptura ao próprio movimento (duplo) de expansão/controle. Algo peculiar, segundo o autor, à formação capitalista.

\begin{abstract}
Como fazer para que a descodificação e a desterritorialização, constitutivas do sistema, não o façam fugir por um ou outro de seus cantos, escapando à axiomática e enlouquecendo a máquina (Deleuze; Guattari, 2011, p. 345)

[...] a função do Estado moderno é a regulação de fluxos descodificados, desterritorializados, um dos principais aspectos desta função consiste em territorializar, de modo a impedir que fluxos descodificados fujam por todos os cantos da axiomática social (Deleuze; Guattari, 2011, p. 342).
\end{abstract}

Como afirmamos, as citações são esclarecedoras dessa função remetida ao Estado na modernidade, o qual, ao deparar-se com as desterritorializações (fundamentais aos fluxos de capital em sua expansão), é chamado a atuar como codificador (controlador) desses mesmos fluxos descodificados. Sendo, portanto, indispensável à própria manutenção da expansão ilimitada. A tentativa de ruptura/fuga desse movimento legado ao Estado democrático liberal, não nos permitiria isentar qualquer outra forma de governo que, porventura, se apresentasse teleologicamente livre da função de controle.

Evidenciando o enunciado acima, o autor pergunta: quais dos regimes, democracia, fascismo ou socialismo, não estariam assombrados por esse Estado (Deleuze; Guattari, 2011)? Independente do regime que o anima, o autor toma a instância estatal como instituição que atualiza constantemente os resquícios do despotismo, para fazer valer na modernidade a função de codificação sobre os diferentes fluxos.

Num primeiro momento, poderíamos supor, ao considerarmos os arrazoados acima, que não sobraria nada, ou quase nada, para pensarmos a democracia como campo de resistência. No intuito de reconsiderar esse suposto corolário, tomamos a micropolítica deleuziana como argumento favorável ao nosso ímpeto de estudar a democracia, não como mero regime de governo representativo ou participativo, mas pelo atravessamento dos devires. Ela não diz sobre uma política em pequena escala, porém sobre a legitimação de um campo de intensidades, de indeterminação e de irredutibilidade às políticas republicanas de governo (Mengue, 2013).

Educação \& Realidade, Porto Alegre, v. 41, n. 2, p. 453-465, abr./jun. 2016. 
Democracia, Micropolítica e os Dispositivos de Gestão Educacional Gerencial

A questão da forma de regime político não estava no centro das preocupações deleuzianas (Mengue, 2013), visto que as institucionalidades democráticas (liberais) apresentam suas mazelas, injustiças, misérias e limitação das liberdades; ou seja, também operam por processos de territorialização, como afirma Deleuze (1992, p. 213):

No capitalismo só uma coisa é universal, o mercado [...]. Ora, ele não é universalizante, homogeneizante, é uma fantástica fabricação de riqueza e de miséria. Os direitos do homem não nos farão abençoar as 'alegrias' do capitalismo liberal do qual eles participam ativamente. Não há Estado democrático que não esteja totalmente comprometido nesta fabricação da miséria humana [...] (grifo nosso).

Portanto, não há condescendência, idealização ou absolutização da democracia, nem de qualquer outra forma ou regime de governo. E, até mesmo, seria incongruente depositarmos esperanças numa imaginária bipolarização, na qual poderíamos tomar a representação como manifestação dos limites e/ou do desvio da democracia e a participação direta como o exemplo perdido da virtude democrática. Não existe margem para esse tipo de compreensão na perspectiva deleuziana.

Referindo-se aos clássicos da filosofia política, poderíamos encontrar elementos indicadores de uma valorização da democracia dos antigos, especialmente na Grécia, como manifestação da participação comum no espaço público e da democracia moderna como definidora da fruição individual, a qual compreende a representação como depositária da vontade de manutenção dos direitos liberais. Rancière (2014) argumenta que a representação em sua origem era o oposto da democracia, contudo, isso não nos autorizaria a opor as virtudes da democracia direta aos desvios da representação, seria falso fazer de uma a refutação da outra.

Poderíamos conjecturar, reafirmando os argumentos anteriores, sobre a preponderância na análise deleuziana voltada ao recrudescimento dos processos liberais na formação do Estado contemporâneo. Sendo assim, seus estudos no campo da filosofia política estavam, mais detidamente, dirigidos à crítica aos direitos dos homens no Estado liberal. Essa compreensão é corroborada pelas afirmações de Mengue (2003), nas quais a democracia (liberal) opõe-se aos eixos fundamentais da filosofia deleuziana. Os valores transcendentais (liberais) supõem um homem abstrato e universal, contrapondo o movimento imanente, tanto no plano da ação como do pensamento; esses também são definidos pelo reino da opinião e do consenso, essencialmente por maioria, fazendo oposição, portanto, aos saberes e práticas menores que são inventivos e apresentam singularidades e multiplicidades. $\mathrm{O}$ consenso dissimula a variedade de forças e de tensões no campo social, funcionando como agente de dominação e repressão; por fim, a concepção de maioria democrática reduz os devires criativos e revolucionários.

460 Educação \& Realidade, Porto Alegre, v. 41, n. 2, p. 453-465, abr./jun. 2016. 
Logo, a preocupação de Deleuze não estava dirigida à constituição de um regime supostamente garantidor dos direitos, mas voltava-se aos devires dos fluxos desterritorializantes, os quais produzem constantes fugas nas organizações instituídas.

[...] como se uma linha de fuga, mesmo que começando por um minúsculo riacho, sempre corresse entre os segmentos, escapando de sua centralização, furtando-se à sua totalização [...] Do ponto de vista da micropolítica, uma sociedade se define por suas linhas de fuga, que são moleculares. Sempre vaza ou foge alguma coisa, que escapa às organizações binárias, ao aparelho de ressonância, à máquina de sobrecodificação (Deleuze; Guattari, 1996, p. 94, grifo nosso).

Nessa orientação, poderíamos afirmar que os regimes democráticos estão sempre sujeitos às fissuras promovidas pelas desterritorializações ou, num possível pleonasmo, expostos a constantes democratizações. Isso acontece porque Deleuze e Guattari (1996) concebiam o campo social como lugar regularmente animado pelos fluxos de fuga/ desterritorializações, mas, ao mesmo tempo, por processos distintos, porém, inseparáveis, de produção de sobrecodificações/territorializações. Ou seja, uma concepção que leva o acontecimento a uma posição de duradoura fuga de si mesmo, visto que ele torna-se assinalável (deixando de ser acontecimento) em algum momento pelas e nas organizações, obrigando-o a ultrapassá-lo novamente pelas próprias dinâmicas de fugas. Logo, a política deleuziana é o constante acontecimento, não redutível aos programas, aos partidos (Mengue, 2013), aos direitos da democracia liberal (Deleuze, 1992, às propostas educacionais que afirmam de antemão as boas e más aprendizagens (Kohan, 2002); uma política sempre por fazer, não teleológica, mas pautada pela indeterminação do acontecimento, pelas intensidades que democratizam a democracia.

A política da indeterminação (ou do virtual) tem sua atuação, sobretudo, no contexto contemporâneo das sociedades de controle. Na sociedade disciplinar, as sujeições e dominações estavam restritas aos espaços institucionais, estando agora inscritas numa arquitetura mais alargada de controle. Concordamos com a concepção segundo a qual as sociedades de controle apresentam identidades híbridas construídas sem as divisões rígidas da disciplina, tornando a produção de subjetividades vinculada a diferentes lugares que perdem suas delimitações e se horizontalizam num amplo campo social, daí, por exemplo, a ideia de formação de um estudante fora da escola (Hardt; Negri, 2001). Conforme Deleuze (1992), as sociedades de controle apresentam seu modo de funcionamento não pelo confinamento institucional, mas pelo controle contínuo de comunicação instantânea. Segundo o autor, a prisão, a escola e o hospital estão em crise e, por ora, em combate de retaguarda promovendo novos tipos de sanções. O próprio campo educacional

Educação \& Realidade, Porto Alegre, v. 41, n. 2, p. 453-465, abr./jun. 2016. 461 
Democracia, Micropolítica e os Dispositivos de Gestão Educacional Gerencial

será cada vez menos um meio fechado, em favor de uma formação permanente, como controle contínuo se exercendo sobre o aluno (e, certamente, sobre o professor). O capitalismo transmuta-se da concentração/produção para a figura de empresas que querem vender serviços e comprar ações, voltado, portanto, para o produto. As instituições como a escola tendem a figuras cifradas (regidas por senhas) de uma empresa de gerentes com metas a cumprir, com avaliação contínua e formação permanente.

Licínio Lima (2007), ao abordar o debate sobre a aprendizagem ao longo da vida, confirma a orientação dominante de formação para adaptabilidade, empregabilidade e vantagens competitivas. Correspondendo aos quesitos da aprendizagem garantidores de competências para competir no mercado global, como estratégia neoliberal que situa a educação como bem de consumo mercadorizado. Com outras palavras, uma educação para a formação de competências empreendedoras, explicitadas na tentativa de demarcação de políticas públicas para a socialização de milhões de jovens como potencial força de trabalho (Evangelista; Leher, 2012). Portanto, professores e alunos são cada vez mais reféns das reformas que subordinam suas atividades a objetivos precisos de socialização para as exigências do mercado.

Talvez pudéssemos fazer alusão à necessidade de estarmos diante das vítimas e dos compromissos que assumimos (Deleuze; Guattari, 1997), mas quem são as vítimas? Não a raça pura, porém a oprimida, a bastarda, a inferior, a anárquica, a nômade, a menor ou, ainda, os analfabetos, os afásicos, os acéfalos. Diante de não é representar ou falar no lugar, mas estar com as vítimas. Estas estão expostas ao pensamento de uma existência que os direciona ao mercado. Os direitos (liberais) no Estado democrático, podemos assim compreender, são os próprios geradores das misérias, e com seus aparatos de segurança pública territorializam os homens pelo e no democrático.

Na sociedade de controle, dos fluxos contínuos de formação educacional, interessa criar condições de atuação nas políticas de governo. O Estado investe numa participação democrática contínua, reinventando súditos, agora com suas inteligências imprescindíveis para afirmação de seu controle (Passetti, 2002) ou, com outras palavras, produz relações sociais, corpos e mentes predispostos a trabalhar, são subjetividades indispensáveis na organização política para a produção do capital na biopolítica (Hardt; Negri, 2001).

Alargar a participação democrática (gerencial) condiz com o desejo de controle amplo disseminado na sociedade, algo bem diferente do modelo disciplinar e seu confinamento institucional. Os novos súditos (as vítimas) produtivos ao capital por meio de suas inteligências, fundamentais ao incremento da riqueza, devem estar vinculados aos aspectos formativos da educação flexível pós-fordista, tanto no momento inicial quanto na permanência da formação ao longo da vida.

462 Educação \& Realidade, Porto Alegre, v. 41, n. 2, p. 453-465, abr./jun. 2016. 
Portanto, a democracia, na versão voltada à gestão educacional, em sua organização de empresa/escola, vem sendo dispositivo de controle e produtividade ao promover a formação para expansão do capital e ao planejar territorializar os fluxos/fugas em desacordo.

Por sua vez, mesmo considerando a amplitude do assédio no chamamento da participação democrática gerencial na sociedade de controle, as vítimas dispõem de estratégias de subversão, de ações desterritorializantes que legitimam a democracia como campo de acontecimentos/devires.

Um primeiro exemplo dessas resistências, num campo social mais amplo, as Jornadas de Junho ${ }^{1}$ apresentaram múltiplas, plurais e descentradas bandeiras de lutas. Sem reducionismos, numa tentativa de síntese, elas culminaram no repúdio à vergonhosa vitaliciedade do domínio de nossas elites políticas; nas críticas aos partidos, dos mais variados espectros, entregues ao maquinismo do poder pelo poder; e da perpétua forma de tornar o público o lugar dos interesses privados. Certamente, as manifestações numa democracia (oligárquica) são legítimas até quando não promovem desvios na ordem estabelecida. No campo da ação democrática, com intensidades desterritorializantes, não há compatibilidade com a redução e limitação da democracia ao mercado.

Num segundo exemplo, cabe lembrar a singela atuação de Maria $^{2}$ (Martins, 2013), professora, nordestina, origem popular e rural, que em sua simplicidade não se rendeu à gestão educacional personalista e centralizada dos gestores escolares e municipais, algo bem comum em algumas cidades. Ela rompeu com o monocratismo, quando suas opiniões foram desconsideradas, desregulamentou o contrato representacional configurado no conselho escolar, mistificador de um pluralismo. As intensidades de suas ações expunham os acordos (pré) definidos pelos gestores e a farsa da gestão democrática, pautada, exatamente, pela responsabilização e pelo financeirismo.

A imagem de educação menor pode ser alvissareira ante o controle que se espraia em nossa sociedade, pois são saberes e práticas que atravessam a pedagogia democrática oficial, promovendo rupturas e/ ou novidades curriculares e organizativas.

Acreditar no mundo significa principalmente suscitar acontecimentos, mesmo pequenos, que escapem ao controle, ou engendrar novos espaços-tempos, mesmo de superfície ou volume reduzidos (Deleuze, 1992, p. 218).

A democracia gerencial (oficial) com seus desdobramentos na educação é submetida à subversão das linhas de fuga da educação menor, as quais buscam escapar à homogeneidade dos significantes existentes na educação e nas imagens dogmáticas estatais constituidoras de uma referência de nação, de um conjunto de cidadãos modelado 
Democracia, Micropolítica e os Dispositivos de Gestão Educacional Gerencial

(Tadeu; Corraza; Zordan, 2004) e das nuances formativas pós-fordistas. Os devires das linhas de fuga se realizam de forma subterrânea, com fluxos que desafiam os dogmas, a imagem da verdade, a ciência magna em suas organizações fechadas etc., são saberes ambulantes os quais promovem experiências de desterritorializações, sempre em vias de se fazer. Diferente de uma concepção opaca dos processos educacionais, como sendo algo que simplesmente reproduz as orientações governamentais, "[...] uma educação menor é um ato de singularização e de militância” (Gallo, 2003, p. 78). As intervenções nos diferentes processos educacionais representam uma trincheira de luta nos quais promovem outros sentidos à educação.

Recebido em 18 de abril de 2015 Aprovado em 28 de março de 2016

\section{Notas}

1 Manifestações populares no Brasil em 2013 que contestavam, inicialmente, o aumento das tarifas do transporte público.

2 Pesquisa realizada numa cidade do interior do nordeste. A(s) Maria(s) afirmam a vida num contexto social e profissional muito adverso.

\section{Referências}

ADRIÃO, Theresa. Educação e Produtividade. A reforma do ensino paulista e a desobrigação do Estado. São Paulo: Xamã, 2006.

BRASIL. Secretaria-Geral da Presidência da República. Democracia Participativa. Nova relação do Estado com a sociedade 2003-2010. 2. ed. Brasília, 2011.

DELEUZE, Gilles. Conversações. Tradução: Peter Pál Pelbart. São Paulo: Editora 34, 1992. DELEUZE, Gilles; GUATTARI, Félix. Mil Platôs. Capitalismo e esquizofrenia (v. 3). Tradução: Aurélio Guerra Neto; Ana Lúcia de Oliveira; Lúcia Cláudia Leão; Suely Rolnik. São Paulo: Editora 34, 1996.

DELEUZE, Gilles; GUATTARI, Félix. O que é Filosofia. 2. ed. Tradução: Bento Prado Jr.; Alberto Alonso Muñoz. Rio de Janeiro: Editora 34, 1997.

DELEUZE, Gilles; GUATARRI, Félix. O Anti-Édipo. Capitalismo e esquizofrenia 1. Tradução: Luiz B. L. Orlandi. 2. ed. São Paulo: Editora 34, 2011.

EVANGELISTA, Olinda; LEHER, Roberto. Todos pela educação e o episódio Costin no MEC: a pedagogia do capital em ação na política educacional brasileira. Trabalho necessário, Universidade Federal Fluminense, ano 10, n. 15, 2012. Disponível em: <http://www.uff.br/trabalhonecessario/images/TN1519\%20Artigo\%20 Roberto\%20Leher\%20e\%20Olinda\%20Evangelista.pdf>. Acesso em: 06 abr. 2013.

FREITAS, Luiz Carlos de. Responsabilização, meritocracia e privatização: conseguimos escapar ao neotecnicismo? In: SEMINÁRIO DE EDUCAÇÃO BRASILEIRA, 3., 2011, Centro de Estudos Educação e Sociedade, Campinas. Anais... Campinas: 2011. Disponível em: <http://www.cedes.unicamp.br/seminario3/ luiz_freitas.pdf $>$. Acesso em: 10 nov. 2014. P. I-F.

GALLO, Silvio. Deleuze e a Educação. Belo Horizonte: Autêntica, 2003. 
HARDT, Michel; NEGRI, Antonio. Império. Tradução: Berilo Vargas. 3. ed. Rio de Janeiro: Record, 2001.

KOHAN, Walter Omar. Entre Deleuze e a educação. Notas para uma política do pensamento. Educação e Realidade, Porto Alegre, v. 27, n. 2, p. 123-130, jul./dez. 2002.

LIMA, Licínio. A Escola como Organização Educativa. Uma abordagem sociológica. 3 ed. São Paulo: Cortez, 2008.

LIMA, Licínio. Educação ao Longo da Vida. Entre a mão direita e a mão esquerda de Miró. São Paulo: Cortez, 2007.

MARTINS, André Antunes. Gestão escolar, democracia, Maria o semiárido e nós. Revista Lugar Comum, Brasil, n. 40, p. 105-118, 2013. Disponível em: $<$ http://uninomade.net/lugarcomum/40/>. Acesso em: 09 set. 2014.

MENGUE, Philippe. Espaço liso e sociedades de controle ou a última política deleuziana. In: GALLO, Silvio; NOVAES, Marcus; GUARIENTI, Laisa Blancy de Oliveira (Org.). Conexões: Deleuze e política e resistência e... Petrópolis: De Petrus et Alii; Campinas: ALB; Brasília: CAPES, 2013. P. 15-34.

MENGUE, Philippe. Deleuze et la Question de la Démocratie. Paris: L'Harmattan, 2003.

OLIVEIRA, Dalila Andrade. A gestão democrática da educação no contexto da reforma do Estado. In: FERREIRA, Naura Syria Carapeto; AGUIAR, Márcia Ângela (Org.). Gestão da Educação. Impasses, perspectivas e compromissos. 8. ed. São Paulo: Cortez, 2011.

PASSETTI, Edson. Anarquismos e sociedade de controle. In: RAGO, Margareth; ORLANDI, Luiz B. Lacerda; VEIGA-NETO, Alfredo. Imagens de Foucault e Deleuze. Ressonâncias nietzschianas. Rio de Janeiro: DPeA, 2002. P. 123-138.

PEREIRA, João Márcio Mendes. O Banco Mundial como Ator Político, Intelectual e Financeiro: 1944-2008. 2008. Tese (Doutorado em História) - Programa de Pós-Graduação em História, Universidade Federal Fluminense, Niterói, 2008.

RANCIÈRE, Jacques. O Ódio à Democracia. Tradução: Mariana Echalar. São Paulo: Boitempo, 2014.

ROBERTSON, Susan. A estranha não morte da privatização neoliberal na Estratégia 2020 para a educação do Banco Mundial. Revista Brasileira de Educação, Rio de Janeiro, ANPEd, v. 17, n. 50, p. 283-302, maio/ago. 2012.

SANTOS, Boaventura de Sousa; AVRITZER, Leonardo. Introdução. Para ampliar o cânone democrático. In: SANTOS, Boaventura de Sousa (Org.). Democratizar a Democracia: os caminhos da democracia participativa. 3. ed. Rio de Janeiro: Civilização Brasileira, 2005. P. 39-82.

STREECK, Wolfgang. Como vai acabar o capitalismo? O epílogo de um sistema em desmantelo crônico. Revista Piauí, Rio de Janeiro, n. 97, p. 52-59, out. 2014.

TADEU, Tomaz; CORAZZA, Sandra; ZORDAN, Paola. Linhas de Escrita. Belo Horizonte: Autêntica, 2004.

André Antunes Martins é doutor em Educação pela Universidade Federal Fluminense/RJ. Atualmente é professor adjunto na mesma universidade do doutoramento. Desenvolve pesquisa no campo das ações coletivas e das políticas públicas com foco na gestão democrática educacional. Também atuou em redes públicas de ensino na educação básica.

E-mail: andreantmartins@gmail.com 